\title{
黄河下游漫滩洪水造床机理与水沙调控 指标研究
}

胡春宏*, 张治昊

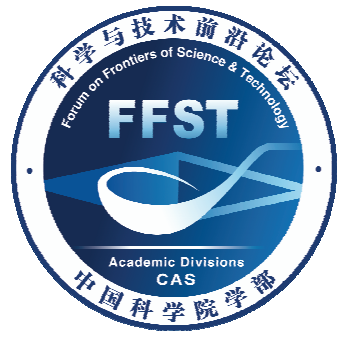

中国水利水电科学研究院流域水循环模拟与调控国家重点实验室, 北京 100038

*E-mail: huch@iwhr.com

收稿日期: 2015-04-11; 接受日期: 2015-07-25

中国水利水电科学研究院专项(编号: SC0145B192014, 沙集 1230)资助项目

摘要本文采用实测资料分析和理论探讨相结合的方法, 系统研究了黄河下游漫滩洪水的造 床机理与水沙调控指标. 结果表明: 对于多沙的黄河, 漫滩洪水最充分的发挥了水流动力的输沙 造床作用, 其削峰滞洪与淤滩刷槽的功效十分显著且不可替代. 漫滩洪水的造床作用随着洪水 漫滩程度的变化而明显不同, 可分为三个阶段; 漫滩初期, 主槽输沙能力降低, 淤滩刷槽作用尚 未得到充分展现; 漫滩中期, 滩槽水沙交换充分, 淤滩刷槽作用良好; 漫滩后期, 淤滩刷槽作用 趋缓. 综合考虑提高河道输水输沙能力与保护滩区防洪安全, 提出的黄河下游有利漫滩洪水的 水沙调控指标为: 洪水漫滩参数 $1.4<\gamma<1.5$ 、来沙系数 $\rho<0.028$, 即按照目前下游河道主槽平滩流 量为 $4000 \mathrm{~m}^{3} / \mathrm{s}$, 通过小浪底水库水沙调控, 控制下泄洪峰流量 $5600 \sim 6000 \mathrm{~m}^{3} / \mathrm{s}$ 、来沙系数小于 0.028 的漫滩洪水, 对于塑造与维持黄河下游合理规模的输水输沙通道最有利. 若控制下游河道 不漫滩, 通过小浪底水库水沙调控, 建议下泄洪峰流量 3500 4000 $\mathrm{m}^{3} / \mathrm{s}$ 接近主槽平滩流量的洪 水, 对于塑造与维持黄河下游合理规模的输水输沙通道较为有利.

\section{1 引言}

复式断面形态是黄河下游河道的基本特征，主 河槽和滩地是河道相互依存的两个主要组成部分, 对于黄河洪水泥沙的处理和河道的塑造具有十分重 要的作用 ${ }^{[1]}$. 当洪水漫滩后, 通过滩槽水沙交换, 黄 河下游河道通常表现为主槽冲深展宽型的淤滩刷槽 演变模式, 此种模式直接扩大了河道主槽的行洪输 沙能力, 在改善泥沙横向淤积分布, 维持主槽不萎缩 等方面具有不可替代的作用 ${ }^{[2]}$. 但是, 由于此种模式 发生于漫滩洪水期, 洪水漫滩必然会给沿岸滩区造
成一定灾害, 在不同的来水来沙条件下, 到底什么样 的漫滩洪水对于黄河下游河道合理规模的输水输沙 通道的塑造与维持是最有利的, 其造床机理与调控 指标是关键的科学问题, 因此, 深入研究主槽冲深展 宽型的淤滩刷槽演变模式, 提出合理的漫滩洪水水 沙调控指标, 利用小浪底水库下泄适当规模的漫滩 洪水, 是缓和维持主槽规模与滩区防洪这一矛盾的 有效途径 ${ }^{[3]}$. 本文分析了漫滩洪水的基本特征; 建立 了淤滩刷槽与漫滩洪水的响应关系、深入探讨了漫滩 洪水淤滩刷槽机理; 在此基础上, 综合分析提出了黄 河下游漫滩洪水的水沙调控指标.

引用格式: 胡春宏, 张治昊. 黄河下游漫滩洪水造床机理与水沙调控指标研究. 中国科学: 技术科学, 2015, 45: 1043-1051 


\section{2 漫滩洪水基本特征}

\section{1 漫滩洪水的水沙特征}

1950 2010 年黄河下游共发生漫滩洪水 53 次, 表 1 为黄河下游漫滩洪水发生机率统计, 图 1 为黄河 下游典型漫滩洪水水沙特征, 由表 1 和图 1 可知: 1) 黄河下游漫滩洪水发生机率呈降低的趋势. 1950 1959 年, 漫滩洪水发生机率达 2.1 次/年; 1960 1973 年, 黄河下游水沙过程受三门峡水库运用 影响较大, 难以反映漫滩洪水发生机率; 1974 1985 年, 漫滩洪水发生机率为 1.4 次/年; 1986 1999 年, 漫 滩洪水发生机率仅为 0.57 次/年; 2000 2010 年, 受小 浪底水库水沙调控, 黄河下游没有发生过自然的漫 滩洪水过程, 仅在 2002 年、2003 年调水调沙期间发 生过 2 次局部漫滩洪水 $\left.{ }^{[4]} .2\right)$ 由于受洪水发生原因、 发生区域不同的影响, 不同场次洪水花园口站洪峰 流量、含沙量时大时小, 表现出很强的随机性. 1950 1959 年, 下游水沙为天然状态, 最大漫滩洪水 发生于 1958 年, 花园口洪峰流量 $22300 \mathrm{~m}^{3} / \mathrm{s}$, 相应含 沙量 $96.6 \mathrm{~kg} / \mathrm{m}^{3} .1960 \sim 2010$ 年, 最大漫滩洪水发生于 1982 年, 花园口洪峰流量 $15300 \mathrm{~m}^{3} / \mathrm{s}$, 相应含沙量 $38.7 \mathrm{~kg} / \mathrm{m}^{3}$, 由此可见, 尽管通过水库水沙调控和上 中游水利水保工程的综合作用, 下游漫滩洪水将得 到一定程度上的削减, 但小浪底水库拦沙运用期有 限, 上中游水土保持措施拦沙作用也有限, 今后黄河 下游发生大漫滩洪水的可能性依然存在 ${ }^{[5]}$.

\section{2 漫滩洪水的削峰滞洪作用}

黄河下游河道上宽下窄, 漫滩洪水的削峰滞洪 作用十分显著. 图 2 为“58.7”洪水洪峰流量沿程变化 图, 由图可见, “58.7”洪水, 花园口-艾山河段洪峰削

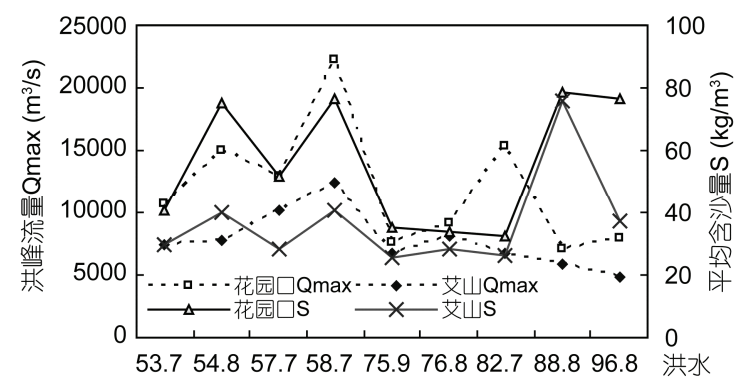

图 1 黄河下游典型漫滩洪水水沙特征

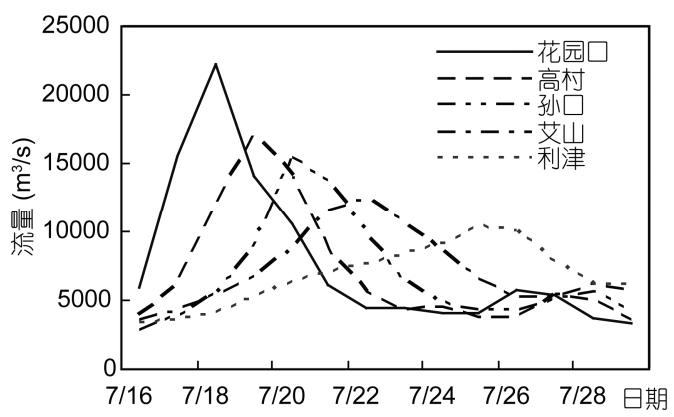

图 2 “58.7”洪水洪峰流量沿程变化图

减值为 $9700 \mathrm{~m}^{3} / \mathrm{s}$, 洪峰削减率高达 $43 \%$, 其中, 夹河 滩-艾山河段的削峰作用最明显. 削峰的同时, 漫滩 洪水的滞洪作用也很显著. “58.7”洪水, 花园口-孙口 河段滞洪量为 $25.89 \times 10^{8} \mathrm{~m}^{3}$, 相当于故县和陆浑水库 的总库容, 大大减轻了下游窄河道的防洪压力 ${ }^{[4]}$.

\section{3 漫滩洪水的淤滩刷槽作用}

黄河下游漫滩洪水的淤滩刷槽作用主要表现为 1) 主槽冲刷, 滩地淤积. 表 2 为黄河下游典型漫滩洪 水滩槽冲淤量统计, 由表可见, 9 次漫滩洪水花园口利津河段主槽冲刷量高达 $26.9 \times 10^{8} \mathrm{t}$, 滩地淤积量高 达 $38.6 \times 10^{8} \mathrm{t}$, 几乎占同期滩地淤积总量的全部，由

表 1 黄河下游漫滩洪水发生机率统计

\begin{tabular}{ccccccc}
\hline 时段 & $1950 \sim 1959$ & $1960 \sim 1964$ & $1965 \sim 1973$ & $1974 \sim 1985$ & $1986 \sim 1999$ & $2000 \sim 2010$ \\
\hline 漫滩洪水发生次数 & 21 & 1 & 4 & 17 & 8 & 2 \\
漫滩洪水发生机率 & 2.1 & 0.2 & 0.44 & 1.4 & 0.57 & 0.18 \\
\hline
\end{tabular}

表 2 黄河下游典型漫滩洪水滩槽冲淤量统计

\begin{tabular}{|c|c|c|c|c|c|c|c|c|c|c|}
\hline \multicolumn{2}{|c|}{ 洪水 } & 53.7 & 54.8 & 57.7 & 58.7 & 75.9 & 76.8 & 82.7 & 88.8 & 96.8 \\
\hline \multirow{2}{*}{ 花艾段 } & 主槽 & -1.79 & -1.17 & -3.23 & -7.1 & -1.42 & -0.11 & -1.54 & -1.05 & -1.5 \\
\hline & 滩地 & 2.2 & 3.43 & 4.66 & 9.2 & 2.14 & 1.57 & 2.17 & 1.53 & 4.4 \\
\hline \multirow{2}{*}{ 艾利段 } & 主槽 & -1.21 & -0.91 & -1.1 & -1.5 & -1.26 & -0.95 & -0.73 & -0.25 & -0.11 \\
\hline & 滩地 & 0.83 & 1.47 & 0.61 & 1.49 & 1.25 & 1.24 & 0.39 & 0 & 0.05 \\
\hline
\end{tabular}


此可见, 尽管漫滩洪水发生的机率不大, 但其输沙造 床作用巨大，对下游河道冲淤具有重要的影响 ${ }^{[6]}$. 2) 主槽冲深展宽, 滩槽高差加大, 过流能力增大, 断面 形态调整以变窄深为主. 图 3 为“58.7”洪水花园口断 面调整图, 由图可见, “58.7”洪水后, 花园口断面主 槽平均冲深 $1.09 \mathrm{~m}$, 横向展宽 $264 \mathrm{~m}$, 左侧滩地淤高 0.2 0.3 m, 主槽平滩面积由 3190 增加到 $3510 \mathrm{~m}^{2}$, 主 槽宽深比由 40 减小为 29.3) 不同时段因水沙及边界 条件变化, 漫滩洪水的淤滩刷槽作用存在差异. 1950 1959 年, 漫滩水流在滩地上的流动没有限制, 再加上主流的摆动, 泥沙能够较均匀地淤积滩地上. 1960 1985 年, 由于受生产堤及“二级悬河”等边界条 件的影响, 漫滩水流横向淤积分布极不均匀, 生产堤 内淤积量大, 生产堤外淤积量少, 造成滩地横比降持 续加大. 1986 1999 年, 受河道萎缩的影响, 小洪水 流量就会发生大漫滩, 沿程滩唇普遍抬高, 滩地横比 降进一步增大, “二级悬河”加剧 ${ }^{[7]}$. 4) 漫滩洪水淤滩 刷槽主要发生在夹河滩-高村、高村-孙口及胨口-利津 河段. “75.9”, “76.8”, “82.7”, “96.8”四场洪水, 夹河滩 -高村、高村-孙口及泺口-利津河段主槽冲刷量分别占 全下游冲刷总量的 $19.9 \%, 25.8 \%$ 和 $30.7 \%$; 滩地淤积 量分别占全下游淤积总量的 $24.9 \%, 34.2 \%$ 和 $19 \%$.

\section{3 淤滩刷槽与漫滩洪水的响应关系}

综合前文分析可知, 对于多沙的黄河, 漫滩洪水 最充分的发挥了水流动力的输沙造床作用, 其削峰 滞洪与淤滩刷槽的功效十分显著且不可替代, 但不 同漫滩程度、不同含沙量洪水对下游河道淤滩刷槽的 效果存在着明显差异, 因此, 需要选择一些能表示淤 滩刷槽与漫滩洪水特征的参数, 研究它们之间的响

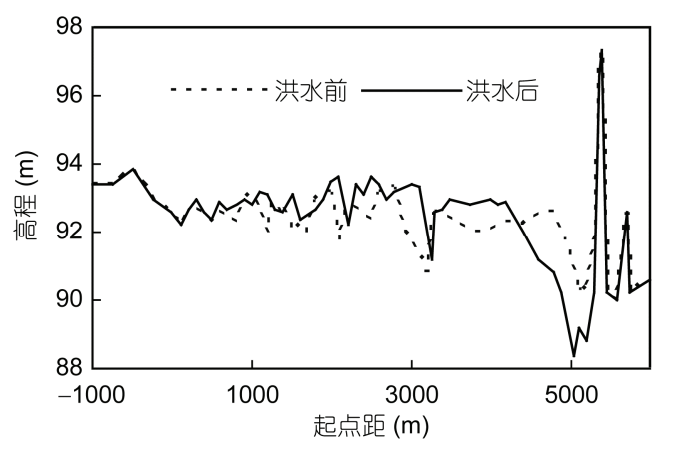

图 3 “58.7”洪水花园口断面调整图
应关系, 揭示漫滩洪水淤滩刷槽规律, 探求漫滩洪水 最佳造床作用的水沙调控区域.

\section{1 滩槽冲淤强度与洪水漫滩程度的关系}

为了研究淤滩刷槽与漫滩洪水的定量关系, 选 择表 2 中所列的黄河下游 9 次典型漫滩洪水作为研究 对象开展相关研究, 首先引入洪水漫滩参数 $\gamma$, 其数 学表达式如下:

$$
\gamma=\frac{Q_{\max }}{Q_{\mathrm{P}}},
$$

式中, $Q_{\max }, Q_{\mathrm{p}}$ 代表某次漫滩洪水花园口站洪峰流量 和洪水前花园口断面的平滩流量, 单位为 $\mathrm{m}^{3} / \mathrm{s}$. 由(1) 式可知, $\gamma$ 表示某次漫滩洪水花园口站洪峰流量相对 于花园口水文断面的平滩流量的大小, 能反映某次 洪水漫滩程度的大小, 是漫滩洪水最重要的表征参 数. 之后, 引入黄河下游河道主槽冲淤强度 $q_{\mathrm{sm}}$, 滩 地冲淤强度 $q_{\mathrm{sf}}$, 其数学表达式如下:

$$
\begin{aligned}
& q_{\mathrm{sm}}=\frac{w_{\mathrm{sm}}}{T}, \\
& q_{\mathrm{sf}}=\frac{w_{\mathrm{sf}}}{T},
\end{aligned}
$$

式中, $W_{\mathrm{sm}}, W_{\mathrm{sf}}$ 分别代表某次漫滩洪水花园口-利津河 段主槽和滩地冲淤量, 单位为亿 $\mathrm{t}, T$ 代表该次漫滩洪 水历时, 单位为 $\mathrm{d}$. 由(2)和(3)式可知, $q_{\mathrm{sm}}, q_{\mathrm{sf}}$ 表示某 次漫滩洪水花园口-利津河段主槽和滩地的日均冲淤 量, 能反映某次漫滩洪水滩槽冲淤强度的大小, 是淤 滩刷槽的重要表征参数.

图 4 为滩槽冲淤强度与洪水漫滩参数关系图, 利 用回归分析的方法分别建立了主槽冲淤强度、滩地冲 淤强度与洪水漫滩参数的相关关系式

$$
q_{\mathrm{sm}}=-0.47 \ln \gamma+0.16 \text {, }
$$

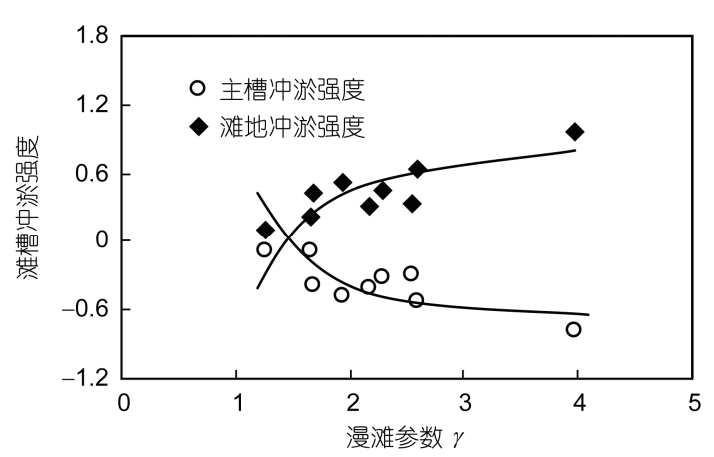

图 4 滩槽冲淤强度与漫滩参数关系图 


$$
q_{\mathrm{sf}}=0.68 \ln \gamma-0.24 \text {. }
$$

(4)和(5)式的相关系数 $R$ 值分别为 0.85 和 0.82 , 表明 滩槽冲淤强度与洪水漫滩参数关系密切. 图 4 中关系 线的变化趋势可以看出, 滩槽冲淤强度随洪水漫滩 程度的变化而变化, 其变化规律为

1) 从总的规律来看, 滩槽冲淤强度随 $\gamma$ 的增大 (减小)而增大(减小). 对主槽而言, 洪水漫滩程度越 大, 在主槽过流能力变化不大的情况下, 说明洪水量 级越大, 洪水量级越大, 主槽的冲刷强度越大; 对滩 地而言, 洪水漫滩程度越大, 滩槽水沙交换作用越强, 进入滩地泥沙越多, 滩地淤积越严重, 所以滩地淤积 强度也随 $\gamma$ 的增大而增大.

2) 在 $\gamma$ 小于 2 左右时, 滩槽冲淤强度随 $\gamma$ 增大而 增大的速度较快; 在 $\gamma$ 大于 2 左右时, 滩槽冲淤强度 随 $\gamma$ 增大而增大的速度有所减缓. 这说明, 当 $\gamma$ 小于 2 左右时, 洪水量级越大, 漫滩程度越大, 滩地淤积越 多, 主槽冲刷越大, 增大洪水量级对于增大淤滩刷槽 作用十分明显; 当 $\gamma$ 大于 2 左右时, 随着漫滩程度的 增大, 主槽冲刷和滩地淤积的强度均有所减缓, 增大 洪水量级对于增大淤滩刷槽作用不太明显.

3) 黄河下游河道淤滩刷槽演变主槽冲淤的临界 水沙条件对漫滩洪水的调控具有重要的现实指导意 义, 故令(4)式等于 0 , 即

$$
-0.47 \ln \gamma+0.16=0 .
$$

由(6)式计算可得, 当 $\gamma$ 为 1.4 时, 黄河下游河道 主槽处于冲淤平衡状态. 由此可知, 对于黄河下游多 场次漫滩洪水平均意义而言, $\gamma$ 小于 1.4 时, 滩地虽然 已有部分入滩水流挟带泥沙的淤积, 而主槽也处于 淤积状态, 尚未开始冲刷; 只有当 $\gamma$ 大于 1.4 时, 主槽 才开始表现为冲刷状态, 漫滩洪水的淤滩刷槽作用 才得以展现.

\section{2 滩槽冲淤强度与洪水水沙搭配的关系}

漫滩洪水来沙系数 $\rho$ 反映了洪水的水沙搭配情 况, 是漫滩洪水的另一个重要表征参数. 图 5 为滩 槽冲淤强度与洪水来沙系数关系图, 利用回归分析 的方法分别建立了主槽冲淤强度、滩地冲淤强度与洪 水来沙系数 $\rho$ 的相关关系式

$$
\begin{aligned}
& q_{\mathrm{sm}}=12.14 \rho-0.34, \\
& q_{\mathrm{sf}}=-10.71 \rho+0.45 .
\end{aligned}
$$

(7)和(8)式的相关系数 $R$ 值分别为 0.79 和 0.78 , 表

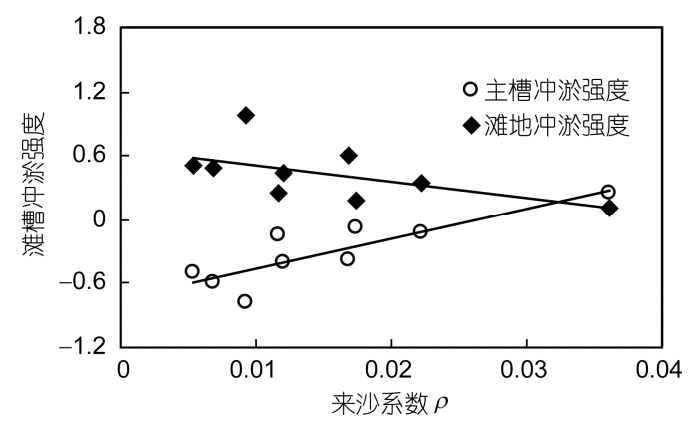

图 5 滩槽冲淤强度与来沙系数关系图

明滩槽冲淤强度与洪水来沙系数的关系比较密切. 图 5 中关系线的变化趋势表明, 滩槽冲淤强度随洪水 来沙系数 $\rho$ 的增大(减小)而减小(增大). 漫滩洪水期, 对主槽而言, 洪水来沙系数越小, 洪水水沙搭配关系 越好, 主槽的冲刷强度越大; 对滩地而言, 洪水来沙 系数越小, 主槽的冲刷强度越大, 滩槽横向及沿程水 沙交换越充分, 进入滩地泥沙越多, 滩地泥沙淤积强 度也就越大 ${ }^{[8]}$. 为得到黄河下游河道淤滩刷槽演变主 槽冲淤的临界水沙条件, 令(7)式等于 0 , 即

$$
12.14 \rho-0.34=0 .
$$

由(9)式计算可得, 当洪水来沙系数 $\rho$ 为 0.028 时, 下游河道主槽处于冲淤平衡状态, 由此可知, 对于多 场次漫滩洪水平均意义而言, 当洪水来沙系数 $\rho$ 小于 0.028 时, 下游河道主槽表现为冲刷状态, 当洪水来 沙系数 $\rho$ 大于 0.028 时, 下游河道主槽表现为淤积 状态.

\section{3 滩槽冲淤效率与洪水漫滩过程的关系}

不仅下游河道滩槽冲淤量是淤滩刷槽的重要表 征参数, 具体到下游河道的每个复式断面, 在洪水漫 滩过程中都能充分展现淤滩刷槽的演变特征. 为了 研究复式断面淤滩刷槽与洪水漫滩过程的关系, 选 择花园口断面作为下游河道的典型代表断面进行研 究, 引入洪水漫滩过程参数 $\gamma_{\mathrm{sd}}$, 其数学表达式如下:

$$
\gamma_{\mathrm{sd}}=\frac{Q_{i}}{Q_{\mathrm{P}}},
$$

式中, $Q_{i}$ 为花园口断面洪水上涨过程中第 $i$ 个时段末 的流量, $Q_{\mathrm{P}}$ 为花园口断面洪水上涨前主槽平滩流量, 由(10)式可知, $\gamma_{\mathrm{sd}}$ 的物理意义为花园口断面洪水上涨 过程中第 $i$ 个时段的漫滩程度. 同时, 引入主槽时段 冲刷效率参数 $\eta_{\mathrm{msd}}$, 滩地时段淤积效率参数 $\eta_{\mathrm{fsd}}$, 其数 学表达式分别如下: 


$$
\begin{gathered}
\eta_{\mathrm{msd}}=\frac{\Delta A_{\mathrm{m} i}}{t_{i}} / \frac{\Delta A_{\mathrm{m}}}{t}, \\
\eta_{\mathrm{fsd}}=\frac{\Delta A_{\mathrm{fi}}}{t_{i}} / \frac{\Delta A_{\mathrm{f}}}{t},
\end{gathered}
$$

式中, $\Delta A_{\mathrm{m} i}, \Delta A_{\mathrm{fi}}$ 分别为花园口断面洪水上涨过程中第 $i$ 个时段主槽增加的冲刷面积和滩地增加的淤积面积, $t_{i}$ 为洪水上涨过程中第 $i$ 个时段的历时; $\Delta A_{\mathrm{m}}, \Delta A_{\mathrm{f}}$ 分别 为花园口断面洪水上涨过程主槽的总冲刷面积和滩 地的总淤积面积, $t$ 为洪水上涨过程总历时; 由(11)和 (12)式可知, $\eta_{\mathrm{msd}}, \eta_{\mathrm{fsd}}$ 的物理意义分别为花园口断面 洪水上涨过程中第 $i$ 个时段主槽冲刷效率和滩地淤积 效率.

图 6(a)利用“58.7”, “82.7”, “96.8”三次漫滩洪水 资料, 点汇了花园口断面主槽时段冲刷效率参数 $\eta_{\mathrm{msd}}$ 和洪水漫滩过程参数 $\gamma_{\mathrm{sd}}$ 关系图, 利用回归分析的方 法建立了 $\eta_{\mathrm{msd}}$ 和 $\gamma_{\mathrm{sd}}$ 的相关关系式

$$
\eta_{\mathrm{msd}}=-0.34 \gamma_{\mathrm{sd}}^{2}+1.37 \gamma_{\mathrm{sd}}-0.21 \text {. }
$$

(13)式的相关系数 $R$ 值为 0.94 , 说明主槽时段冲刷效 率参数 $\eta_{\mathrm{msd}}$ 和洪水漫滩过程参数 $\gamma_{\mathrm{sd}}$ 的关系非常密切. (13)式表明, $\eta_{\mathrm{msd}}$ 与 $\gamma_{\mathrm{sd}}$ 是二次多项式的关系, 利用二 次多项式的基本性质推导可得

$$
\begin{gathered}
\gamma_{\mathrm{sd}}=-\frac{b}{2 a}=2.01, \\
\max \left(\eta_{m s d}\right)=-\frac{b^{2}}{4 a}+c=1.17 .
\end{gathered}
$$

即当洪水漫滩过程参数 $\gamma_{\mathrm{sd}}$ 为 2.01 时, 主槽时段冲刷
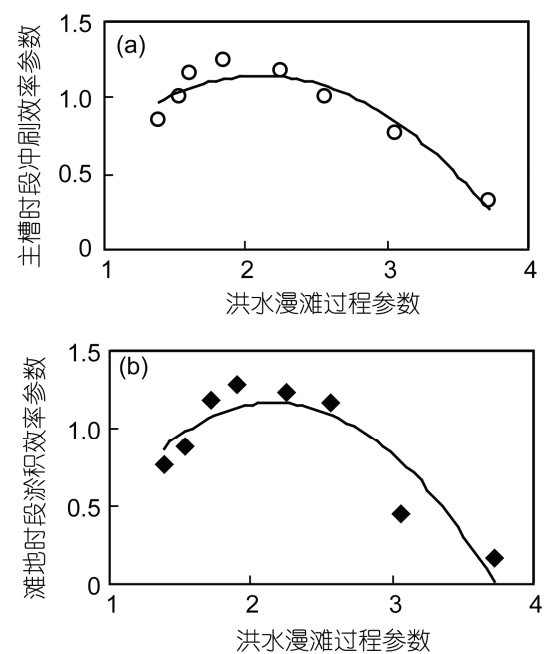

图 6 花园口断面滩槽冲淤效率与洪水漫滩过程的响应 关系
效率参数 $\eta_{\mathrm{msd}}$ 达到了最大值 1.17 .

图 6(b)点汇了花园口断面滩地时段淤积效率参 数 $\eta_{\mathrm{fsd}}$ 和洪水漫滩过程参数 $\gamma_{\mathrm{sd}}$ 关系图, 利用回归分析 的方法建立了 $\eta_{\mathrm{fsd}}$ 和 $\gamma_{\mathrm{sd}}$ 的相关关系式

$$
\eta_{\mathrm{fsd}}=-0.47 \gamma_{\mathrm{sd}}^{2}+1.92 \gamma_{\mathrm{sd}}-0.75 \text {. }
$$

(16)式的相关系数 $R$ 值为 0.92 , 说明滩地时段淤积效 率参数 $\eta_{\mathrm{fsd}}$ 和洪水漫滩过程参数 $\gamma_{\mathrm{sd}}$ 的关系非常密切. (16)式表明, $\eta_{\mathrm{fsd}}$ 与 $\gamma_{\mathrm{sd}}$ 也是二次多项式的关系, 利用 二次多项式的基本性质推导可得

$$
\begin{gathered}
\gamma_{\mathrm{sd}}=-\frac{b}{2 a}=2.04, \\
\max \left(\eta_{\mathrm{fsd}}\right)=-\frac{b^{2}}{4 a}+c=1.21 .
\end{gathered}
$$

即当洪水漫滩过程参数 $\gamma_{\mathrm{sd}}$ 为 2.04 时, 滩地时段淤积 效率参数 $\eta_{\mathrm{fsd}}$ 达到了最大值 1.21. 分析(13)和(16)式变 化趋势线可知, 两条曲线的变化趋势基本相同, 随着 漫滩程度增大, 主槽时段冲刷效率和滩地时段淤积 效率均呈增大的趋势; 当洪水漫滩过程参数 $\gamma_{\mathrm{sd}}$ 达到 2.01 时, 主槽时段冲刷效率参数率先达到了最大值, 稍后, 当 $\gamma_{\mathrm{sd}}$ 达到 2.04 时, 滩地时段冲刷效率参数也 达到了最大值; 之后, 随着漫滩程度进一步增大, 主 槽时段冲刷效率和滩地时段淤积效率均呈减小的趋 势. 这就从典型复式断面微观变化的角度验证了图 4 中得到的当 $\gamma$ 大于 2 左右时, 滩槽冲淤强度均有所减 缓的结论是合理的. 主槽时段冲刷效率参数达到最 大值时, $\gamma_{\mathrm{sd}}$ 为 2.01 ; 滩地时段冲刷效率参数达到最大 值时, $\gamma_{\mathrm{sd}}$ 为 2.04 ; 表明滩槽水沙交换需要一定的时间, 所以滩地淤积的变化相对于主槽冲刷的变化具有一 定的滞后性.

\section{4 漫滩洪水的淤滩刷槽机理分析}

黄河下游漫滩洪水的淤滩刷槽特征, 在洪水漫 滩的不同阶段, 表现与效果明显不同. 根据前文漫滩 洪水特征, 可利用洪水漫滩参数 $\gamma$ 将洪水上涨过程划 分为 3 个阶段

$$
\begin{gathered}
1<\gamma<1.4, \text { 漫滩初期; } \\
1.4<\gamma<2, \text { 漫滩中期; } \\
\gamma>2, \text { 漫滩后期. }
\end{gathered}
$$

按照上述划分, 下面分别对三个阶段漫滩洪水 淤滩刷槽机理进行重点分析. 
4.1 漫滩初期一该阶段滩唇初步形成, 主槽输沙 能力降低, 滩槽水沙交换不充分, 淤滩刷槽作用尚 未得到充分展现

一维泥沙数学模型常用的河床变形方程 ${ }^{[3]}$

$$
\gamma^{\prime} \frac{\partial Z}{\partial t}=\alpha \omega\left(S-S_{*}\right) .
$$

由(19)式可知, 河床冲淤主要取决于水流挟沙力 $S *$ 与水流含沙量 $S$ 的对比关系, $\left(S-S_{*}\right)$ 值大于 0 , 小于 0 , 等于 0 分别表示河床处于淤积、冲刷、冲淤平衡 三种状态. (19)式右侧水流挟沙力 $S$ *的一般表达式如 下 $^{[1]}$ :

$$
S_{*}=K\left(\frac{U^{3}}{g h \omega}\right)^{m} .
$$

图 7 为“96.8”洪水涨水阶段花园口断面水位流速 关系图, 由图可见, 漫滩初期, 主槽流速由随水位升 高呈增大的趋势变为随着水位升高呈减小的趋势, 由(20)式可知, 主槽流速的减小, 导致主槽水流挟沙 力 $S$ *的减小. 由(19)式可知, 假设尚未漫滩前, 主槽 处于淤积状态, 漫滩后主槽水流挟沙力 $S_{*}$ 的下降会 加大主槽水流挟沙力 $S_{*}$ 与洪水含沙量 $S$ 的差值, 使得 漫滩初期主槽的淤积加重; 假设尚未漫滩前, 主槽处 于冲刷状态, 漫滩后主槽水流挟沙力 $S$ *的下降会使 得漫滩初期主槽的冲刷减弱. 对于滩地而言, 漫滩初 期, 滩地水流宽浅散乱, 滩地水流流速小, 导致滩地 水流挟沙力 $S$ 也较小; 而进入滩地的水流含沙量与 主槽含沙量基本相当, 远大于滩地水流挟沙力, 所以 滩地淤积程度较重, 由于漫滩宽度的限制, 淤积的部 位主要集中于滩槽交接处, 形成滩唇. 滩唇的形成使 得滩地横比降 $J$ 加大, 水流的横向流动强度加大, 主 槽进入滩地的水量增大, 滩地的淤积会进一步加重. 所以, 当 $1<\gamma<1.4$ 时, 淤滩作用已经展现, 而主槽输

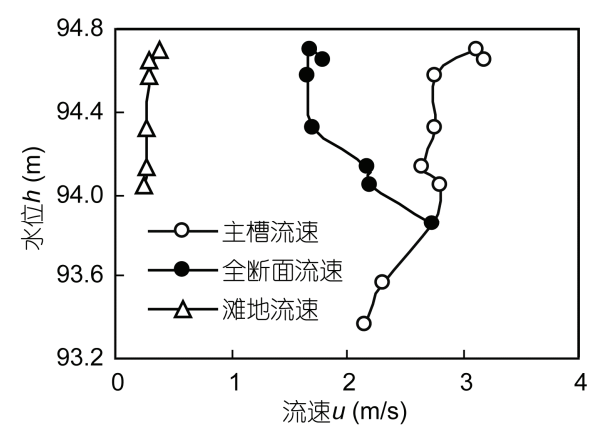

图 7 “96.8”洪水涨水阶段花园口断面水位流速关系图
沙能力的降低使得刷槽作用尚未得到充分展现.

\section{2 漫滩中期一该阶段滩地淤积与主槽冲刷相互} 促进，滩槽水沙交换充分，淤滩刷槽作用良好

由图 7 可见, 当洪水漫滩到一定程度, 主槽流速 止住了随水位升高而减小的趋势, 之后, 表现为随水 位升高而迅速增大的趋势. 主槽流速持续增大，主槽 水流挟沙力 $S_{*}$ 必然持续增大, 主槽冲刷会逐渐趋强. 主槽冲刷增强的另一个原因是滩唇的抬高改善了主 槽的断面形态. 引入主槽断面形态特征参数 $\pi$, 其数 学表达式如下:

$$
\pi=\frac{p}{R},
$$

式中, $p$ 为主槽湿周, $R$ 为主槽水力半径. 河道水流连 续方程和曼宁公式如下 ${ }^{[9]}$ :

$$
\begin{gathered}
Q=A V=P R V, \\
V=\frac{1}{n} R^{\frac{2}{3}} J^{\frac{1}{2}} .
\end{gathered}
$$

(22)和(23)式中, $Q$ 为主槽流量, $n$ 为主槽粮率, $J$ 为主 槽纵比降. 联解式(21) (23) 可得

$$
V=\left(\frac{\sqrt{J}}{n}\right)^{3 / 4}\left(\frac{Q}{\pi}\right)^{1 / 4} .
$$

由(24)式可知, 当洪水漫滩到一定程度时, 滩唇 的持续抬高增加了滩槽高差, 主槽断面形态特征参 数 $\pi$ 减小, 主槽断面形态变得窄深, 主槽流速有所增 大, 主槽水流挟沙力 $S_{*}$ 相应增大, 主槽冲刷得以增 强.

影响滩地淤积的主要因素包括: 进入滩地的洪 水水量 $W$, 滩地水流挟沙力 $S *$ 和滩地水流含沙量 $S$, 其定性关系式可表达如下:

$$
w_{s}=k\left[w\left(S-S_{*}\right)\right]^{m} .
$$

由图 7 可见, 滩地流速随水位升高而增大的幅度 较小, 滩地水流挟沙力 $S_{*}$ 增大的幅度也必然较小, 所 以，此时滩地 $\left(S_{-} S_{*}\right)$ 差值依然很大; 同时, 由于进入 滩地的水量 $W$ 越来越大, 由(25)式可知, 滩地淤积量 必然增大. 此阶段水流的横向流动大大增强, 将水流 中的泥沙带到滩地纵深处淤积, 使滩地横比降增大 的趋势有所减缓.

随着进入滩地水量的增大, 滩地淤积量增大, 使 得回归主槽的水量增大, 主槽水流含沙量 $S$ 降低, 主 槽水流挟沙力 $S$ 增大, 主槽水流冲起的床沙增多, 相 
应进入滩地的主槽床沙也就增多, 由于主槽床沙较 粗, 滩地水流挟沙力 $S *$ 降低, 滩地的淤积增大, 所以, 主槽的冲刷与滩地的淤积是相互促进的关系, 滩地 的淤积促进了主槽的冲刷, 而主槽冲起的粗颗粒泥 沙又会加剧滩地的淤积. 综合上述分析, 当 $1.4<\gamma<2$ 时, 滩槽水沙交换充分, 主槽发生了剧烈冲刷, 滩地 发生了大量淤积, 而且其淤积分布较为合理, 淤滩刷 槽作用良好.

\section{3 漫滩后期一该阶段主槽流速增幅减小, 河床 粗化, 滩槽水沙交换减少, 淤滩刷槽作用趋缓}

当 $\gamma>2$ 时, 主槽冲刷减缓的原因有: 1) 进入二滩 的水量增多, 造成嫩滩内水量增加呈减少的趋势, 主 槽水位升高的速度减缓, 主槽流速增大的速度也减 缓. 图 8 为“58.7”洪水花园口断面主槽流速与流量的 关系图, 由图可见, 花园口流量较小时, 主槽流速增 大的速度较快, 流量大于 $8000 \mathrm{~m}^{3} / \mathrm{s}$ 后, 主槽流速增 大的速度越来越慢, 导致主槽水流挟沙力增大的速 度也越来越慢, 主槽的冲刷逐渐变缓. 2) 主槽河床的 粗化, 也会导致主槽冲刷减弱. 随着主槽冲刷的持续 发展, 主槽床沙会越来越粗, 床沙变粗, 提高了床沙 沉速 $\omega$, 进而降低水流挟沙力 $S_{*}$, 主槽水体从床沙中 得到泥沙补充越来越困难, 主槽的冲刷也就逐渐变 缓. 3) 二滩蓄水容量很大, 又有生产堤阻隔, 相对封 闭, 这些都会导致二滩内的水量不能及时回归滩地 下游的主槽, 从而降低了主槽的沿程冲刷强度.

当 $\gamma>2$ 时, 滩地淤积变缓的原因有: 1) 嫩滩淤积 减缓. 嫩滩是滩槽水沙交换最直接、最频繁的部位, 随着主槽冲刷变缓, 从主槽冲起的泥沙减少, 相应由 滩槽水沙交换至嫩滩的泥沙也减少, 嫩滩的淤积逐 渐减缓. 2) 二滩沿程淤积减缓. 上游窄河段主槽冲刷 逐渐减缓, 由上游窄河段主槽进入下游宽河段二滩 的水流含沙量逐渐降低, 泥沙数量逐渐减小, 此时,

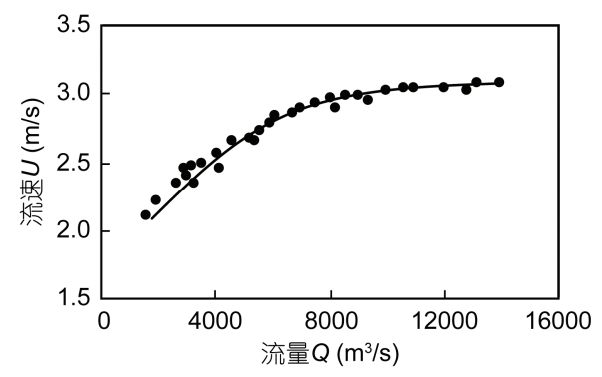

图 8 “58.7”洪水花园口断面主槽流速与流量关系图
在二滩自身水流挟沙力 $S$ *变化不大的情况下, 二滩 沿程的淤积也将逐渐减缓.

\section{5 漫滩洪水水沙调控指标}

1999 年小浪底水库投入运用后, 利用小浪底水 库调控进入下游河道的漫滩洪水水沙过程成为可能, 在此背景下, 提出适宜的漫滩洪水水沙调控指标, 对 于小浪底水库调水调沙运用具有重要的现实指导意 $义^{[3]}$.

前文的研究表明, 从淤滩刷槽的效果与造床作 用来看, 一方面, 不宜施放 $1<\gamma<1.4$ 的洪水, 因为此 类洪水不能充分发挥扩大主槽行洪能力的作用, 同 时, 由于漫滩宽度的限制, 此类洪水在滩地的泥沙淤 积部位主要集中于滩槽交接处, 极易形成和抬高滩 唇, 加大滩地横比降, 严重威胁黄河下游防洪安全. 另一方面, 也不宜施放 $\gamma>2$ 的洪水, 因为主槽流速增 幅减小、河床粗化以及滩槽水沙交换减少导致此类洪 水的淤滩刷槽作用明显减弱.

而当 $1.4<\gamma<2$ 时, 滩槽水沙交换充分, 淤滩刷槽 作用良好, 所以, 通过小浪底水库水沙调控, 下泄漫 滩程度适中的洪水过程, 对于提高河道输水输沙能 力十分有利. 小浪底水库十多年的蓄水拦沙运用, 黄 河下游河道普遍冲刷, 目前, 下游河道主槽平滩流量 已恢复至 $4000 \mathrm{~m}^{3} / \mathrm{s}$ 左右, 依据(1)式计算可得, 从有 利于下游河道演变的角度出发, 小浪底水库应下泄 洪峰流量 5600 $8000 \mathrm{~m}^{3} / \mathrm{s}$ 的漫滩洪水过程. 同时, 黄 河下游滩区涉及沿黄 43 个县(区), 共有村庄 1928 个, 人口 189.5 万人, 耕地 340 万亩 ${ }^{[8]}$, 长期以来, 为保护 生命财产安全和发展生产的需要, 滩区人民修建了 大量的生产堤, 依据目前滩区内生产堤的修建规模 对黄河下游防洪影响的初步分析结果表明 ${ }^{[10]}$, 当黄 河下游发生小于 $6000 \mathrm{~m}^{3} / \mathrm{s}$ 流量级漫滩洪水时, 生产 堤能够较大程度上的保护滩区的防洪安全, 减轻洪 水漫滩造成的灾害损失; 一旦漫滩洪水超过了 6000 $\mathrm{m}^{3} / \mathrm{s}$ 流量级, 生产堤决口的概率增大, 滩区防洪安全 的威胁陡然增大, 造成的灾害损失会明显加重. 综合 考虑提高河道输水输沙能力, 塑造有利的输水输沙 通道及保护滩区防洪安全, 应充分利用黄河下游河 道现有的生产堤条件, 使洪水适当漫滩, 结合前文研 究得到的下游漫滩洪水主槽冲淤临界水沙条件, 提 出的有利漫滩洪水水沙调控指标为: 洪水漫滩参数 
$1.4<\gamma<1.5$ 、来沙系数 $\rho<0.028$, 即按照下游河道主槽 平滩流量为 $4000 \mathrm{~m}^{3} / \mathrm{s}$, 通过小浪底水库水沙调控, 控制下泄洪峰流量 5600 6000 $\mathrm{m}^{3} / \mathrm{s}$, 来沙系数小于 0.028 的漫滩洪水过程, 对于塑造与维持黄河下游合 理规模的输水输沙通道最有利. 当然, 上述洪峰流量 的调控指标主要是结合目前黄河下游滩区的实际情 况提出的, 比较接近 $\gamma=1.4$ 的下限水平, 相信随着滩 区治理水平的不断提高, 未来将洪峰流量的调控指 标逐步提高至 $\gamma=2$ 的上限水平(即 $8000 \mathrm{~m}^{3} / \mathrm{s}$ 流量) 是 可以实现的.

特别需要指出的是, 考虑到近年来黄河来水来 沙及滩区安全的实际情况, 暂不能允许下泄漫滩洪 水, 则建议通过小浪底水库水沙调控, 控制下泄洪峰 流量 3500 4000 $\mathrm{m}^{3} / \mathrm{s}$ 接近主槽平滩流量的洪水过程, 对于塑造与维持黄河下游合理规模的输水输沙通道 较为有利.

\section{6 主要结论}

1) 受水库运用及人类活动影响, 黄河下游漫滩 洪水发生机率呈降低的趋势, 今后黄河下游发生大 漫滩洪水的可能性依然存在. 尽管漫滩洪水发生的 机率不大, 但漫滩洪水最充分的发挥了水流动力的 输沙造床作用, 其削峰滞洪与淤滩刷槽的功效十分 显著且不可替代. 1960 1985 年, 由于受生产堤及“二 级悬河”等边界条件的影响, 洪水漫滩后, 滩地淤积 横向分布极不均匀, 滩地横比降持续加大；1986
1999 年, 受下游河道萎缩的影响, 小洪水流量就会 发生大漫滩，沿程滩唇普遍抬高, “二级悬河”加剧.

2) 漫滩洪水的造床作用随着洪水漫滩程度的变 化而明显不同，可分为三个阶段；漫滩初期，滩唇初 步形成, 主槽输沙能力降低, 滩槽水沙交换不充分, 淤滩刷槽作用尚未得到充分展现; 漫滩中期, 滩槽水 沙交换充分，主槽发生了剧烈冲刷，滩地发生了大量 淤积，而且其淤积分布较为合理，淤滩刷槽作用良好. 漫滩后期, 主槽冲刷和滩地淤积的强度均减缓; 且主 槽冲刷减缓对于滩槽水沙沿程交换的影响要持续一 段时间才能在滩地淤积上得以体现，所以滩地淤积 变缓具有一定的滞后性.

3) 综合考虑提高河道输水输沙能力与保护滩区 防洪安全，应充分利用黄河下游河道现有的生产堤 条件, 使洪水适当漫滩, 据此提出的有利漫滩洪水水 沙调控指标为: 洪水漫滩参数 $1.4<\gamma<1.5$ 、来沙系数 $\rho<0.028$, 即按照目前下游河道主槽平滩流量为 4000 $\mathrm{m}^{3} / \mathrm{s}$, 通过小浪底水库水沙调控, 控制下泄洪峰流量 $5600 \sim 6000 \mathrm{~m}^{3} / \mathrm{s}$, 来沙系数小于 0.028 的漫滩洪水, 对 于塑造与维持黄河下游合理规模的输水输沙通道最 有利. 特别需要指出的是, 考虑到近年来黄河来水来 沙情况及滩区安全的实际情况, 暂不能允许下泄漫 滩洪水, 则建议通过小浪底水库水沙调控, 控制下泄 洪峰流量 3500 4000 $\mathrm{m}^{3} / \mathrm{s}$ 接近主槽平滩流量的洪水, 对于塑造与维持黄河下游合理规模的输水输沙通道 较为有利。

\section{参考文献}

1 胡春宏. 黄河水沙过程变异及河道的复杂响应. 北京: 科学出版社, 2005

2 吴保生, 张原锋, 申冠卿, 等. 维持黄河主槽不萎缩的水沙条件研究. 郑州: 黄河水利出版社, 2010

3 胡春宏, 陈建国, 郭庆超, 等. 黄河水沙调控与下游河道中水河槽塑造. 北京: 科学出版社, 2007

4 潘贤娣, 李勇, 张晓华, 等. 三门峡水库修建后黄河下游河床演变. 郑州: 黄河水利出版社, 2006

5 胡春宏, 张治昊. 黄河下游河道萎缩过程中洪水水位变化研究. 水利学报, 2012, 8: 883-890

6 姚文艺, 苏运启, 李勇. 黄河下游排洪输沙基本功能的影响因素及判别指标. 泥沙研究, 2009, 2: 1-9

7 李文学, 李勇, 张晓华. 黄河下游河道行洪能力对河道萎缩的响应关系. 中国科学 E 辑, 2004, 34: 126-132

8 胡春宏, 张治吴. 黄河下游复式河道滩槽分流特征研究. 水利学报, 2013, 1: 1-9

9 徐正凡. 水力学. 北京: 高等教育出版社, 1982

10 申冠卿, 曲少军. 黄河下游滩区生产堤对防洪影响的研究报告. 郑州: 黄河水利科学研究院, 2007 


\title{
The research of mechanism of constructing riverbed and index of flow and sediment of floodwater in the Lower Yellow River
}

\author{
HU ChunHong \& ZHANG ZhiHao
}

State Key Laboratory of Simulation and Regulation of Water Cycle in River Basin, China Institute of Water Resources and Hydropower Research, Beijing 100038, China

Using the methods of field data analyses and theoretical study, the mechanism of constructing riverbed and index of flow and sediment of floodwater is researched in the Lower Yellow River. The results show that floodwater exert transporting sediment and constructing riverbed adequately, it can lower flood peak and store floodwater and aggrade floodplain and scour channel. The overflowing floodwater can be divided into three phases. In earlier phase, the floodplain aggradation and channel scour has not been exhibited; in metaphase, flow and sediment exchange of the floodplain and channel is sufficient, the floodplain aggradation and channel scour effect is good; in anaphase, the floodplain aggradation and channel scour slower. Synthesis considering riverbed evolvement and the security of floodplain, the controlling indexes are the overflowing parameter $1.4<\gamma<1.5$, the incoming sediment coefficient $\rho<0.028$. At present, the bankfull discharge of the Lower Yellow River resume $4000 \mathrm{~m}^{3} / \mathrm{s}$, in favor of figuring and maintaining logical size of channel, through the controlling of Xiaolangdi reservoir, the peak discharge of ejective floodwater should be $5600-6000 \mathrm{~m}^{3} / \mathrm{s}$, the incoming sediment coefficient should be less than 0.028 . If controlling floodwater can not overflowing, the peak discharge of ejective floodwater should be $3500-4000 \mathrm{~m}^{3} / \mathrm{s}$ approaching the bankfull discharge.

Lower Yellow River, overflowing floodwater, floodplain aggradation and channel scour, mechanism of constructing riverbed, flow and sediment controlling

doi: 10.1360/N092015-00012 